\title{
Deudores, rentistas y prácticas crediticias en la sociedad leonesa. El ejemplo de la ciudad de Astorga en los siglos XVII y XVIII
}

\author{
Laureano M. Rubio Pérez *
}

\section{LAS FORMAS DE FINANCIACIÓN: OBLIGACIONES Y CENSOS "AL QUITAR»}

A pesar de que actualmente aún no se puede hablar de la existencia de una plétora de trabajos específicos ${ }^{1}$ sobre el crédito privado y sus formas de imposición en la España moderna, la historiografia general española y los estudios históricos de conjunto ya han aportado alguna luz al conocimiento de esas formas crediticias conocidas bajo la denominación de censos, generalmente consignativos o al quitar, y obligaciones o ventas «al fiado" ${ }^{2}$. A su vez, en las últimas décadas estudios concretos al respecto,

* Universidad de León.

1 Un importante estudio sobre la tipología documental que nos ofrecen los protocolos notariales es el de A. EIRAS ROEL: “Tipología Documental de los protocolos gallegos", La historia social de Galicia en sus fuentes de protocolo, Santiago 1981, pp. 21-113.

${ }^{2}$ En las obras clásicas de la historiagrafía moderna destaca un primer planteamiento hecho por Carmelo VIÑAS MEY: El problema de la tierra en la España de los siglos XVI y XVII, Madrid 1941, pp. 49-52, que ve al censo como un medio de endeudamiento, asi como medio fácil para adquirir la tierra hipotecada.

A su vez, N. SALomon en La vida rural castellana en la época de Felipe II, Barcelona 1973 , p. 255, defiende la tesis para el siglo XVI de que el censo fue «instrumento de sujeción del campesino" "que le llevó, caso de no poder cumplir el contrato, a convertirse en "vasallo del nuevo amo".

V. VAZOUEZ dE PRADA en la Historia económica y social de España. Siglos xVI y xVII, vol. III, pp. 687-694, recoge los planteamientos de Viñas Mey si bien, apunta la conveniencia de "ser cautos al enjuiciar la problemática de los censos, pues nos faltan estudios esclarecedores suficientes". 
fuera del marco general de una obra histórica de conjunto y sobre distintas áreas de la geografía española, han puesto de manifiesto que, si bien en el fondo y en la forma se dan grandes similitudes en el desarrollo y función del crédito privado moderno, también se hallan importantes peculiaridades y diferencias en función de los medios económicos existentes, así como de los grupos sociales que conviven con diferentes medios e intereses en una clara relación de interdependencia ${ }^{3}$.

${ }^{3}$ Actualmente no sólo han salido a la luz estudios concretos sobre estas formas crediticias, sino también trabajos de carácter regional que plantean los aspectos diferenciales regionales. De este conjunto se pueden destacar: B. BEnNASSAR: Valladolid en el siglo de Oro. Una ciudad de Castilla y su entorno agrario en el siglo xvi, Valladolid 1983, pp. 240253. El autor hace un análisis de los prestatarios y de los prestamistas de la ciudad de Valladolid y su área rural en el siglo xvi. De su estudio se desprenden importantes diferencias con las tierras leonesas en los siglos siguientes, sobre todo referente a los prestamistas (pp. 248-249). E. FERNANDEZ DE PINEDO: Crecimiento económico y transformaciones sociales en el País Vasco 1100-1800, Madrid 1974, pp. 289-317.

A. Marcos Martin: Economia, Sociedad, pobreza en Castilla: Palencia, 1500-1814, t. I, pp. 300-328.

L. RuBio Pérez: La Bañeza y su Tierra, 1650-1850. Un modelo de sociedad rural leonesa. Los hombres, los recursos y los comportamientos sociales, León 1987.

Dentro de los trabajos específicos sobre las formas de financiación destacamos los siguientes:

B. ESCANDEL: "Las investigaciones de los contratos de préstamos hipotecarios (censos). Aportación a la metodología de series documentales uniformes". Actas I.J.M.A.C.H., t. III. Santiago 1975, pp. 751-762.

J. FERREIRO PORTO: “Fuentes para el estudio de las formas del crédito popular en el A. régimen: obligaciones-préstamo, ventas de renta y ventas de censos", Actas de I.J.M.A.C.H., t. III, Santiago 1975, pp. 763-780.

T. HeRNANDEZ SEMPERE: "La inscripción de censos en Albalat de la Ribera: propuestas para un estudio sobre el crédito privado en el campo valenciano durante el setecientos". Actas de I.C. sur le Pays Valencien a l'epoque moderne, 1980, pp. 283-313.

B. BENNASSAR: "Consumation, investissements, mouvements de capitaux en Castille aux XVI et XVII siècies", Conjoncture économique, structures sociales. Hommage à E. Labrousse. Paris 1974, pp. 139-155.

V. VAZOUEZ DE PRADA: «Protocolos notariales e historia económica: crédito, comercio e industria", Actas de // C.M.H.A., t. II, Santiago 1984, pp. 189-218.

U. GOMEZ ÁlvarEZ: "Obligaciones y censos: dos intrumentos de endeudamiento popular en el Principado de Asturias. Siglos XVII y XVIII", Actas de II C.M.H.A., Santiago 1984, t. II, pp. 381-394.

A. FloRistán ImIzCOZ: "Crédito rural en Navarra. Los censos al quitar". Actas de II C.M.H.A., t. II, Santiago 1984, pp. 395-408.

También es de destacar la tesis pionera de U. Gómez Álvarez: Estudio histórico de los préstamos censales del Principado de Asturias(1680-1715). Luarca 1979. Así como las importantes valoraciones de A. EIRAS ROEL sobre la función de obligaciones y censos para la economía española del A. Régimen en "La economía española en la época de los Austrias", pp. 448 y en "La burguesía mercantil compostelana a mediados del sigio XVIII: mentalidad tradicional e inmovilismo económico", La historia social de Galicia en sus fuentes de protocolos, Santiago 1981, pp. 521-564. 
Así pues, tanto los censos al quitar como las obligaciones cubrieron una importante etapa en la historia de la sociedad moderna, como instrumento de crédito privado generador de una nueva relación y dependencia social entre los diversos grupos que componen la sociedad maragata. Unos los censualistas y prestamistas que canalizaban hacia sí los excedentes agrarios, otros los prestatarios y censatarios que buscaban recursos financieros, ya para subsistir, ya para abordar un gasto importante.

Ahora bien, en el caso que nos ocupa como en otros ya conocidos en la provincia leonesa ${ }^{4}$, el nivel de utilización de estas formas crediticias varió a lo largo de los siglos por causas que intentaremos explicar más adelante, desmarcándose de las pautas seguidas por otras tierras del conjunto nacional ${ }^{5}$, pues si consideramos que las Obligaciones también fueron un instrumento de crédito, éstas durante el siglo XVII y, sobre todo, durante el XVIII, no sólo superaron cuantitativamente a los censos, sino que llegaron a desbancarlos, convirtiéndose en la forma más usual en este tipo de relaciones socio-económicas.

No obstante, el censo fue el instrumento de crédito mejor estructurado y reglamentado de la Edad Moderna, remontándose sus origenes al siglo XIII, si bien hasta el XVI no se configura y se desarrolla plenamente ${ }^{6}$. Este censo «al quitar» fue hasta el siglo XVIII la forma más directa para que determinados grupos sociales, sobre todo campesinos y artesanos propietarios, pudieran conseguir capital o dinero en un momento en el que, como afirma Vázquez de Prada, el préstamo con interés calificado como usura era radicalmente rechazado, tanto por las normas y autoridades civiles como por las eclesiásticas ${ }^{7}$.

Este carácter especulador al que podia llegar este tipo de préstamo así como el cuestionar la función que cumplió, fueron factores que motivaron el rechazo, la crítica y el debate entre moralistas, hombres de leyes y arbitristas de la época como Cellorigo, Ceballos, Ripia, Sancho de Moncada, etc. Incluso las propias autoridades civiles intervinieron contra los censualistas reduciendo el tipo de interés legal a fijar en los contratos de venta. Así, en la primera mitad del siglo xvi el interés era relativamente

${ }^{4}$ En la vecina villa de La Bañeza la importante burguesía comercial constituia la mayoria de las Obligaciones con el área rural.

${ }_{5}^{5}$ Hacemos referencia a que VAZQUEZ DE PRADA en Historia económica.., p. 687 afirma que el censo "es el instrumento de crédito más utilizado en la Edad Moderna".

${ }^{6}$ B. Bennassar: Valladolid..., p. 241.

7 V. VAzQuez de Prada: Historia económica..., p. 687. 
alto y oscilaba entre el 10 y el 16 por 100 , aunque muy pronto es reducido por las cortes al 7,14 por 100 , hasta que las mismas Cortes de 1609 lo fijan en 20.000 al millar lo que equivale al 5 por 100 , y posteriormente en 1705 Felipe $V$ reduce definitivamente el tipo de interés censal al 3 por $100^{8}$, lo que no impide que durante el siglo XVIII se constituyan censos al 2,5 por 100 , cuando es abundante la oferta de capital ${ }^{9}$.

Por lo que respecta a las denominadas obligaciones es palpable una menor dedicación por parte de la historiografia, a pesar de que, como afirmamos anteriormente, es la forma más usual de crédito indirecto y el motor que dinamiza la comercialización de los productos en los propios mercados junto a una relación más directa entre prestamistas o fiadores y prestatarios o compradores.

La característica fundamental de estas Obligaciones $y$, por consiguiente diferencia con respecto al censo, se sitúa en un doble aspecto: el primero de carácter temporal, ya que mientras el plazo de imposición censal queda a voluntad del censatario o tomador, en la Obligación se da el plazo corto que por lo general no excede de un año, buscando siempre la devolución o el pago en meses claves del año cosecha en los que el campesino tiene mayores posibilidades de saldar la deuda contraida. el segundo se refiere al propio carácter, pues, mientras el censo es un "auténtico contrato de compra-venta» en el que se especifica una hipoteca que garantiza la recuperación del capital y unos intereses junto a todo tipo de condiciones ${ }^{10}$, las obligaciones son escrituras notariales de reconocimiento público de una deuda en las que se expresan unas intenciones y se acepta la decisión y penas judiciales caso de incumplir lo acordado en el contrato. En tercer lugar, a la vez que el censo sigue un modelo único estandarizado en donde sólo varia la cuantía del capital y la hipoteca, la obligación abarca toda una gama de escrituras de reconocimiento de deudas, ventas al fiado, préstamos, etc. A su vez, la obligación no exige la presencia de una hipoteca, pues el pago queda garantizado por solventes fiadores.

Son, pues, muchas las diferencias tipológicas y estructurales, como también lo son las funciones que durante el siglo XVII y XVIII desarrollaron

${ }^{8}$ B. ESCANDEL: “Las investigaciones...», p. 755.

9 A. Marcos Martín: Economía, sociedad..., pp. 306-307. Encuentra imposiciones en el siglo XVIII al 2,5 por 100.

${ }_{10}$ U. Gómez Álvarez: Obligaciones..., p. 384. 
ambas formas crediticias, sobre todo en el área rural maragata situada bajo la influencia de la ciudad de Astorga como centro administrativo jurisdiccional civil y religioso.

Ahora bien, dado que estas formas o medios de financiación se desarrollan en el seno social conviene hacer un balance de los grupos sociales y su influencia en la zona de estudio, lo que nos ayudará a comprender mejor los resultados obtenidos.

En la comarca leonesa de Maragatería o Somozas contamos durante la Edad Moderna y Contemporánea con dos mundos bien diferenciados: uno el rural, situado en las estribaciones del Teleno; y el otro urbano, en la ciudad de Astorga, que figura como importante centro administrativo y comercial. El área rural maragata nos presenta una economía agraria pobre, con graves condicionantes geográficos tanto en el clima como en el suelo, economía que se asienta sobre el cereal de secano en barbechos anuales (centeno) y el ganado ovino. Estos factores condicionantes, junto a la insuficiencia de recursos, llevó a parte de esta sociedad rural ya desde la Edad Media a buscar recursos complementarios en el comercio. Su asentamiento a medio camino entre Galicia y Castilla facilitó el que entre el 20 y el 30 por 100 de sus familias ${ }^{11}$ pudieran compartir la agricultura con la actividad arriera entre los puertos gallegos y los centros neurálgicos castellanos (Madrid, Valladolid, etc.).

Junto a este espacio rural se alza la bimilenaria ciudad de Astorga cuya estructura social la define durante la Edad Moderna como un centro religioso, tanto secular como regular, de primer orden, en el que conviven las oligarquías clericales diocesanas con otros grupos seglares rentistas e hidalgos. Junto a éstos una reducida burguesía comercial extiende su área de influencia no sólo sobre la comarca, sino también sobre otras tierras leonesas como el alto Bierzo, la Cepeda, la Ribera, etc. Fruto de esta activa relación con una amplia área rural durante el siglo XVIII se consolida, aunque en menor medida que en la vecina villa de La Bañeza, una burguesía hidalga comercial que mantiene estrechos lazos de interdependencia con el campesino. Junto a ésta, los representantes de la nobleza y de la administración, todos hidalgos, tienen una destacada participación en la actividad económica, sobre todo en la canalización de los recursos procedentes de las rentas y en la actividad crediticia. Pero

$"$ L. Rubio PÉREZ: «Análisis demográfico-social de una comarca leonesa. La Maragatería durante el Antiguo Régimen", Estudios Humanisticos, n. ${ }^{\circ}$ 7, León 1985, p. 128. 
$1620-1629$

$1630-1639$

$1640-1649$

$1650-1659$

$1660-1669$

$1670-1679$

$1680-1689$

$1690-1699$

1700-1709

1710-1719

$1720-1729$

$1730-1739$

$1740-1749$

$1750-1759$

$1760-1769$
47

154

38

232

78

130

67

175

66

186

85

34

21

94

56

107

47

43

32

44

20

153

0

45

0

40

1

32

31 
$1770-1779$

$1780-1789$

1790-1799

1800-1806
23

13

3

0
12

11

15

2

en la ciudad de Astorga son, sin duda, el clero regular (conventos de Sta. Clara, Santi Spíritus, etc) y el secular (mesa capitular de la catedral) los grandes perceptores de los excedentes agrarios y, por consiguiente, los poseedores del posible capital inversor, por lo que convierten a esta ciudad en el siglo XVII, y desde el punto de vista del crédito censal, como el centro financiero más importante de la provincia junto a la capital, León.

\section{Los censos}

\subsection{Evolución de las imposiciones censales}

La escribanía de número y ayuntamiento de la ciudad de Astorga nos permite, a través de sus índices, seguir durante dos siglos los ritmos impositivos de estas formas crditicias censales, así como las redenciones de censos realizadas en su movimiento anual y decenal. (Ver cuadro anterior).

Del presente cuadro y de las correspondientes gráficas se desprende que el censo tiene su mayor fase de desarrollo durante el siglo XVII. La curva del movimiento anual de las imposiciones refleja en la década de los años treinta del siglo XVII el primer incremento de la demanda de capital censal que precede al fuerte incremento de las dos décadas siguientes, caracterizadas en la provincia leonesa por el despertar y primer 
despliegue de la producción agraria y de la población, después de la larga crisis anterior. A la vista de esto, creemos que existe una relación entre ambas variables, pues la fuerte demanda de capital censal fue el remedio buscado por el campesino para salir de la crisis, animado por la presencia de una nueva fase alcista.

Hasta 1680 las imposiciones censales se mantienen en niveles muy altos que alcanzan durante el año 1645 los 49 censos, pero la caída se hace manifiesta en las dos décadas finales de ese mismo siglo. La grave crisis de los años ochenta paraliza, en cierta medida, el desarrollo de las imposiciones censales y al igual que ocurriera durante las primeras décadas del siglo, el campesino, en plena crisis económica, no se atreve a solicitar unos préstamos que, por otra parte, difícilmente sabe si podrá pagar sus intereses. Incluso la oferta de capital censal se reduce por parte de los grupos privilegiados o rentistas.

A pesar de todo, la curva de imposiciones censales vuelve a recuperarse entre 1690 y 1705, cuando nuevamente las variables económicas nos sitúan en un ciclo positivo y de recuperación, aunque a raiz de las crisis anuales de la primera década del siglo XVIII, de nuevo, y hasta 1730 , el nivel impositivo de los censos es reducido. Junto a esta inestabilidad económica agraria se produce ahora la reducción de los tipos de interés de los censos al 3 por 100, lo que provoca una desviación de capital de las oligarquias seglares y del clero secular hacia otras formas de inversión más rentables (Obligaciones). La década situada entre 17251735 refleja un ciclo económicamente expansivo con importante recuperación de la producción agraria leonesa. Es aquí donde arranca el proceso expansivo agrario del siglo XVIII, lo que unido a las buenas perspectivas de una agricultura en auge, de una población en ascenso y de la puesta en marcha de los sectores dependientes, secundarios y comerciales, explica que se reactive la demanda de créditos y de capital, ahora no sólo por parte del campesino que ve la posibilidad de ampliar sus explotaciones comprando tierra y ganado, sino también de otros grupos sociales relacionados con la actividad comercial que solicitan este dinero barato inclusive para especular con sus negocios, con lo que el censo como medio de financiación corriente en el siglo XVII se hace ahora mucho más selectivo.

Desde mediados del siglo XVIII los censos decaen progresivamente $y$, aunque con excepciones, solamente los campesinos acomodados y la burguesía comercial junto a profesiones liberales pueden beneficiarse de ellos. Ahora, los censualistas quedan reducidos al clero regular ya que lo 
otros grupos e instituciones rentistas buscan mejores y más rentables formas de inversión, bien directas o indirectas mediante la adquisición de medios de producción (ganado o tierra preferentemente).

Por otra parte, el ritmo de las redenciones de censos es muy similar al de las imposiciones, si bien es de resaltar que entre 1730 y 1760 apenas se producen estas redenciones, lo que puede significar que los censatarios vean más benefioso el disponer de ese capital por el que pagan bajos intereses que cerrar la deuda, sobre todo durante esa transcendental fase económica del siglo XVIII.

\subsection{Características técnicas del préstamo censal}

\section{a) El capital}

A mediados del siglo XVIII el capital de los censos existentes es mas bien reducido, pues el 35 por 100 de ellos sitúan el principal en 550 reales y el 30,3 por 100 lo hacen en 1.100 reales. En mucha menor medida se hallan los censos cuyo principal es superior a los 2.000 reales, tal como se aprecia en el cuadro de la página siguiente.

Así pues, el denominado capital es la cantidad de dinero que el centualista entrega al censatario sobre el que se impone el tipo de interés.

Aunque no hay una norma establecida sobre la cuantía del capital o principal se aprecian algunas diferencias entre los censos de los diversos grupos sociales pues, mientras los censos del clero secular rural y cofradías raramente superan los 1.000 reales, los del clero regular $(50 \%)$ sitúan el principal entre los 1.000 y los 3.000 reales, siendo la excepción los que superan dicha cantidad ${ }^{12}$. No obstante, más de la mitad de los censos constituidos durante el siglo XVIII establecen el principal en torno-

${ }^{12}$ Solamente determinados censos solicitados por la nobleza alcanzan cantidades importantes que pueden superar los 10.000 reales. Este es el caso de la marquesa de Astorga que en 1752 mantiene constituido un censo de 9.900 reales por los que paga anualmente al cabildo 297 reales de réditos. AHPL. Caja 7926. 


\begin{tabular}{|c|c|c|c|c|}
\hline REALES & $\mathrm{N}^{\circ}$ CENSOS & $\%$ & $\begin{array}{l}\text { TOTAL CAPITAL } \\
\text { REALES }\end{array}$ & $\begin{array}{c}\text { TOTAL INTERESES } \\
\text { REALES }\end{array}$ \\
\hline 366 & 5 & 7,6 & 1.830 & 55 \\
\hline 550 & 23 & 35 & 12.650 & 379,5 \\
\hline 660 & 6 & 9 & 3.960 & 116 \\
\hline 770 & 3 & 4,5 & 2.310 & 69 \\
\hline 880 & 2 & 3 & 1.760 & 53 \\
\hline 1.100 & 20 & 30,3 & 22.000 & 660 \\
\hline 1650 & 2 & 3 & 3.300 & 98 \\
\hline 2.000 & 1 & 1,5 & 8.800 & 264 \\
\hline TOTAL & 66 & 100 & 58.610 & $1.763,5$ \\
\hline
\end{tabular}

a los 1.100 reales y 33 de réditos, apreciándose durante este siglo una tendencia a la constitución de censos cuyo capital supera los 1.000 reales, lo que puede ser una muestra más de que esta forma crediticia se hace más selectiva y de que los grupos sociales demandantes poseen importantes recursos o bienes a hipotecar que son mayores cuanto mayor sea el capital recibido.

b) La hipoteca

La fundación de un censo conllevó el establecimiento de una hipoteca sobre bienes perfectamente localizables y cuyo valor debía incluso superar al capital prestado. En la práctica, en la totalidad de los censos, 
la hipoteca se hace sobre casas y tierras. Generalmente el campesino hipoteca, además de la casa y la huerta, alguna tierra, siempre las de mejor calidad (prados, linares, etc.), mientras que los grupos urbanos lo hacen sobre casas y huertas.

De la firma forma que otras cargas sobre estos bienes inmuebles como las fundaciones, las hipotecas censales sujetaron la tierra, produciendo graves perjuicios a la hora de disponer de ella por parte de los propietarios. En el contrato censal las condiciones asumidas por ambas partes sobre el propio capital y su hipoteca son muy claras y por ellas el tomador del préstamo se compromete a velar por el sostenimiento del valor de la hipoteca ${ }^{13}$.

Además, para una mayor seguridad y control por parte de lus censualistas se impide cualquier enajenación o cambio de los bienes hipotecados, sin previo consentimiento ${ }^{14}$. Este control sobre la hipoteca conlleva la no división de los bienes hipotecados, lo que tuvo importantes repercusiones en la propia estructura de la tierra ${ }^{15}$.

Pero también el censatario tiene a su favor el que puede disponer libremente del capital y solamente bajo su consentimiento se puede dar por finalizado el contrato, o parte de él, previa devolución del capital y de los intereses devengados ${ }^{16}$.

${ }^{13}$ AHPL, Caj. 10178 (2021): «... que las dichas tres casas ypotecadas siempre las he de tener y mis heredeos tendran bien avonadas e reparadas de todos los avonos y reparos nezesarios de forma que baian en aumento y no vengan en disminuzion y si asi no lo hiziese e hizieren quiero y consiento que la dicha cofradia o quien fuere señor deste censo se entre reparandolas y abonandolas de lo que nezesitasen y por lo que importasen dichos reparos e materiales e de ser egecutado..."

${ }_{14} \mathrm{AHPL}$, Ibidem: "... que dichas casas hipotecadas no se han de poder trocar, cambiar ni enegenar a persona poderosa, dueña, doncella, hospital, cofradia, ni de fuera destos reinos, y caso que se haga dicha enagenacion a de ser a persona lega llana, abonada de quien bien y llanamente se pueda cobrar el principal y reditos de este censo con tal que antes de celebrar el contrato se ha de avisar a la dicha cofradia o quien fuere señor del censo que si las quisiere que al tanto sea preferido a qualquier comprador..."

15 AHPL, Caj. 9489 (461): “... que dichas casas hipotecadas no se an de poder partir ni dividir entre dos ni más herederos porque siempre estaran en un solo poder y poseedor lego y acionado de quien bien y llanamente se pueda cobrar dicho principal y reditos".

${ }^{16}$ AHPL, Caj. 10189 (2032): “... que siempre que yo o mis herederos subzesores poseedores de dichas casas quisieramos redimir este dicho censo o la mitad de el a de ser visto poderlo hazer y la dicha cofradia o quien fuere señor de el ha de estar obligado a to recibir y otorgar carta de pago y redenzion y no queriendolo hazer lo cumplieren y cumpliran con depositarlo ante la justizia desta villa...". 


\subsection{Los censualistas}

Uno de los aspectos claves en el estudio de estas formas de financiación es el conocimiento de la procedencia social de los censualistas, si bien, no es de sorprender que, al igual que en el resto de las tierras españolas, la iglesia y, sobre todo el clero regular, acapare más del 80 por 100 del capital censal.

A través de una gran muestra de escrituras censales procedente de los índices de la notaría astorgana de número y ayuntamiento se ha podido analizar la actitud inversora de los distintos grupos y organizaciones sociales durante los siglos XVII y XVIII (Ver cuadro siguiente).

\begin{tabular}{|c|c|c|c|c|c|c|c|c|}
\hline \multirow{2}{*}{ CENSUALISTAS } & \multicolumn{2}{|c|}{$1620-1650$} & \multicolumn{2}{|c|}{$1650-1700$} & \multicolumn{2}{|c|}{$1700-1750$} & \multicolumn{2}{|c|}{$1750-1810$} \\
\hline & & & $n .^{\circ}$ & $\%$ & & $\%$ & $n .^{\circ}$ & $\%$ \\
\hline Fábrica iglesias .. & 15 & 3,9 & 17 & 2,9 & 9 & 6,2 & 6 & 7,3 \\
\hline Cofradias...$\ldots \ldots \ldots$ & 20 & 5,2 & 44 & 7,5 & 12 & 8,3 & 18 & 21,9 \\
\hline Clero rural & 11 & 2,9 & 3 & 0,5 & 6 & 4,1 & 0 & 0 \\
\hline Clero urbano & 145 & 37,8 & 72 & 12,2 & 29 & 20 & 8 & 9,8 \\
\hline Conventos $\ldots \ldots \ldots \ldots$ & 75 & 19,6 & 249 & 42,3 & 66 & 45,8 & 42 & 51,2 \\
\hline Laicos con Don & 54 & 14 & 101 & 17,2 & 11 & 7,6 & 5 & 6,1 \\
\hline Laicos sin Don & 47 & 12,3 & 90 & 15,3 & 6 & 4,2 & 3 & 3,6 \\
\hline Profes. liberales & 15 & 3,9 & 12 & 2 & 5 & 3,5 & 0 & 0 \\
\hline Concejos & 1 & 0,3 & 0 & 0 & 0 & 0 & 0 & 0 \\
\hline TOTAL ... & 383 & 100 & 588 & 100 & 144 & 100 & 82 & 100 \\
\hline
\end{tabular}

Como se desprende de la presente tabla, los distintos sectores eclesiásticos acaparan durante todo el período el mayor porcentaje de capital censal, no obstante se aprecia alguna variación a destacar durante los 
dos siglos de estudio. En primer lugar, la fuerte incidencia inversora del clero secular astorgano en la primera mitad del siglo XVII con un 37,8 por 100 de los censos constituidos, lo que se explica si tenemos en cuenta que estamos en una villa que cuenta con una numerosa presencia del clero secular en torno a la catedral. Con el 19,6 por 100 el clero regular se sitúa también a la cabeza de la posesión de censos. Ambos hacen de Astorga un centro importante de captación de excedente agrario por medio de las rentas e impuestos $y$, por consiguiente, un centro financiero en el que, sobre todo en el siglo XVIII, los distintos sectores sociales deficitarios, principalmente el campesino, acuden en busca de capital y de recursos.

Frente a una más bien escasa participación en el censo de iglesias y cofradías asi como del clero rural, cosa lógica por parte de estos últimos dado que, como veremos, asientan sus escrituras en las escribanías locales de los centros jurisdiccionales, es de destacar en esta primera mitad del siglo XVII la participación de los laicos (hidalgos y pequeña nobleza) con el 14 por 100 de los censos, y de sectores comerciales con el 12,3 por 100, así como las profesiones liberales entre los que destacan los propios notarios con un 3,9 por 100 , que se mantendrán hasta mediados del siglo XVIII en esos niveles de inversión.

En la segunda mitad del siglo xVII se experimenta ya alguna variación, dado que el clero urbano secular pasa a un segundo orden después del clero regular, descendiendo los censos a su favor al 12,2 por 100, a la vez que las órdenes religiosas acaparan el 42 por 100 de los censos constituidos, manteniéndose los otros sectores sociales en los mismos niveles. Pero durante las primeras décadas del siglo XVIII la distribución de los censos va a variar sustancialmente, sobre todo a raíz de la reducción del interés al 3 por 100 y de la presencia de unas coyunturas que favorecen otras inversiones más rentables.

Aunque el clero secular astorgano incrementó su presencia en el capital censal por razones coyunturales, el clero regular mantiene, con el 45,8 por 100 , cerca de la mitad de los censos constituidos, a la vez que cofradías e iglesias parroquiales incrementan algún punto con respecto a la fase anterior y los sectores laicos, nobleza $(7,6 \%)$ o burguesía comercial $(4,2 \%)$, se van apartando progresivamente de este tipo de inversión.

La segunda mitad del siglo XVIII marca nuevas diferencias, ya que, frente a un sostenimiento de los conventos $(51,2 \%)$, el clero secular astorgano con sólo el 9,8 por 100 de los censos parece haber elegido 
también nuevas formas de inversión, mientras que las cofradias parecen buscar una mayor seguridad inversora, sobre todo ante los ataques que el Gobierno lanza contra sus recursos inmuebles. Esto hace que de un 8,3 por 100 de los censos del período anterior pasen a constituir el 21,9 por 100 en las últimas décadas cuando ya eran escasos los censos.

Se produce así una clara situación diferenciadora entre los distintos grupos y estamentos sociales. Por un lado, el clero regular y las cofradías buscan en el siglo XVIII la seguridad inversora frente a los inconvenientes de otras inversiones más rentables como las obligaciones. Por otro, el clero secular y las oligarquías ciudadanas laicas buscan formas más rentables para su dinero, aún a costa de mayores riesgos minimizados ahora por las perspectivas coyunturales.

Los resultados obtenidos sobre los censos de las escribanías rurales maragatas se ajustan a los anteriores y son los previstos:

IMPOSICIONES CENSALES

CENSUALISTAS

$1620-1650 \quad 1650-1700 \quad 1700-1750 \quad 1750-1810$

n. ${ }^{\circ} \%$ n. $\%$ n. $\%$ n. ${ }^{\circ} \%$

Parroquias

$0 \quad 0 \quad 6$

$6,8 \quad 1$

$4,5 \quad 2$

12,5

Cofradías

$\begin{array}{lll}6 & 11,8 & 15\end{array}$

17

$\begin{array}{lll}5 & 22,7 & 6\end{array}$

37,5

Clero rural

13

$25,5 \quad 33$

37,5

$\begin{array}{lll}5 & 22,7 & 6\end{array}$

37,5

Clero urbano

$8 \quad 15,7$

910,2

2

Conventos 14

$27,5 \quad 15$

$15 \quad 17$

$\begin{array}{ll}9 & 41\end{array}$

$\begin{array}{ll}6 & 37,5\end{array}$

Hidalgos

$\begin{array}{lll}5 & 9,8 & 8\end{array}$

Prof. liberales

59,8

$8 \quad 9$

$\begin{array}{lll}9 & 0 & 0\end{array}$

00

2

2,3

$0 \quad 0 \quad 0$

TOTAL 
En el área rural maragata (escribanía de Lucillo) el clero secular rural y los conventos astorganos se llevan más del 50 por 100 de los censos pero, mientras que la alta participación de los segundos se mantiene alcanzando en la primera mitad del siglo el 41 por 100 de los censos, el clero local hace descender su participación de forma progresiva durante el siglo XVIII hasta el 12,5 por 100 . Aqui, tanto la hidalguía como las profesiones liberales dejan de constituir censos en el siglo XVIII y las cofradías junto al clero rural son las protagonistas y dueñas del capital censal. Estas cofradías rurales parecen ocupar en la segunda mitad del siglo XVIII el espacio dejado por el clero astorgano, ya que pasan del 17 por 100 de la segunda mitad del siglo XVII al 37,5 por 100 de los censos de la segunda mitad del siglo XVIII. Las iglesias parroquiales cuya participación era escasa en el primer siglo, en las últimas décadas del XVIII su presencia en el capital censal alcanza al 12,5 por 100 de los censos.

Se puede valorar, pues, de escasa la práctica inversora en censos por parte de los sectores no eclesiásticos, lo que hace a estos sectores o grupos eclesiásticos, principales perceptores de las rentas agrarias, los verdaderos e importantes censualistas; tal como, además, se puede comprobar a través del catastro de 1752.

\section{DISTRIBUCIÓN DE LOS PRÉSTAMOS CENSALES A MEDIADOS DEL SIGLO XVIII EN ASTORGA (ECLESIÁSTICOS)}

\begin{tabular}{|c|c|c|c|c|c|c|c|}
\hline \multirow{2}{*}{ PROPIETARIOS } & \multicolumn{2}{|c|}{ CENSOS } & \multicolumn{2}{|c|}{ CAPITALES } & \multicolumn{3}{|c|}{ REDITOS } \\
\hline & N. ${ }^{\circ}$ & $\%$ & Reales & $\%$ & Reales & Marv. & $\%$ \\
\hline Cabildo & 19 & 11,17 & 62.792 & 27,15 & 1.895 & & 27,2 \\
\hline Parroquias & 16 & 9,4 & 13.492 & 5,8 & 405 & 30 & 5,8 \\
\hline
\end{tabular}

Cofradías:

$\begin{array}{lrrrr}\text { Sta. Bárbara } \ldots \ldots & 6 & 4.620 & 136 & 30 \\ \text { De la Cruz } \ldots \ldots \ldots & 4 & 3.600 & 108 & \\ \text { Sto. Angel } \ldots \ldots \ldots & 2 & 3.640 & 109 & 20 \\ \text { S. José } \ldots \ldots \ldots & 1 & 720 & 22 & \\ \text { Proto-Martín ........ } & 16 & 7.397 & 222 & \\ \text { S. Andrés ........ } & 8 & 5.350 & 157 & \end{array}$




\begin{tabular}{|c|c|c|c|c|c|c|c|}
\hline \multirow{2}{*}{ PROPIETARIOS } & \multicolumn{2}{|c|}{ CENSOS } & \multicolumn{2}{|c|}{ CAPITALES } & \multicolumn{3}{|c|}{ RÉDITOS } \\
\hline & $\mathrm{N} .^{\circ}$ & $\%$ & Reales & $\%$ & Reales & Marv. & $\%$ \\
\hline 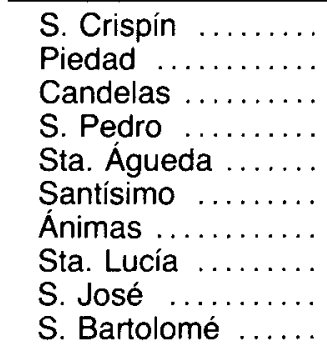 & $\begin{array}{l}2 \\
5 \\
2 \\
3 \\
2 \\
5 \\
6 \\
3 \\
4 \\
1\end{array}$ & & $\begin{array}{r}1.320 \\
3.423 \\
1.340 \\
1.605 \\
1.400 \\
2.346 \\
5.700 \\
2.420 \\
864 \\
330\end{array}$ & & $\begin{array}{r}39 \\
103 \\
40 \\
48 \\
42 \\
71 \\
171 \\
72 \\
26 \\
9\end{array}$ & $\begin{array}{r}30 \\
20 \\
4 \\
4 \\
\\
6 \\
4 \\
28\end{array}$ & \\
\hline $\begin{array}{l}\text { TOTAL } \\
\text { COFRADÍAS } \ldots . . . .\end{array}$ & 70 & 41,17 & 46.075 & 19,9 & 1.380 & & 19,8 \\
\hline \multicolumn{8}{|l|}{ Conventos: } \\
\hline $\begin{array}{l}\text { S. Dictino } \ldots \ldots \ldots \\
\text { Sti. Spiritus } \ldots \ldots \\
\text { Sta. Clara } \ldots \ldots\end{array}$ & $\begin{array}{l}10 \\
10 \\
22\end{array}$ & $\begin{array}{r}5,9 \\
5,9 \\
12,9\end{array}$ & $\begin{array}{l}12.958 \\
27.147 \\
29.249\end{array}$ & $\begin{array}{r}5,6 \\
11,7 \\
12,7\end{array}$ & $\begin{array}{l}390 \\
816 \\
876\end{array}$ & 30 & $\begin{array}{r}5,6 \\
11,7 \\
12,6\end{array}$ \\
\hline $\begin{array}{c}\text { TOTAL CLERO } \\
\text { REGULAR } \ldots . . . . .\end{array}$ & 42 & 24,7 & 69.354 & 30 & 2.082 & & 29,9 \\
\hline Fundaciones . & 2 & 1,17 & 2.800 & 1,2 & 84 & & 1,2 \\
\hline Clero secular & 7 & 4,11 & 14.702 & 6,35 & 460 & & 6,6 \\
\hline Capellanes coro ..... & 13 & 7,64 & 10.068 & 4,35 & 306 & & 4,4 \\
\hline Hospital S. Juan ..... & 1 & 0,6 & 12.000 & 5,2 & 360 & & 5,2 \\
\hline TOTAL & 170 & 100 & 231.289 & 100 & 6.973 & & 100 \\
\hline
\end{tabular}

De la presente relación se descubre una fuerte presencia de las cofradias en la propiedad del capital censal, muy superior a la ofrecida 
por las fuentes notariales $(41,1 \%$ ) que, junto al 24,7 por 100 del clero regular se pueden considerar como los grandes censualistas.

Sin embargo, es de destacar que el clero regular alcanza el 30 por 100 del capital censal frente a sólo el 19,9 por 100 de las cofradias y del 27,1 por 100 del capital cabildo que solamente se apropia del 11 por 100 de los censos. Esto indica la menor cuantía del principal de los censos de las cofradías, frente a un nivel muy superior en el capital censal cedido tanto por los conventos como por el cabildo astorgano.

En el área rural, tal como vimos anteriormente, cofradías y conventos astorganos con el 41 por 100 son la principal fuente de capital censal, frente a una insignificante participación de los seglares:

\begin{tabular}{|c|c|c|c|c|c|c|}
\hline \multirow{2}{*}{ PUEBLO } & \multicolumn{6}{|c|}{ CENSUALISTAS $\left(N^{\circ}{ }^{\circ}\right.$ DE CENSOS) } \\
\hline & $\begin{array}{l}\text { Clero } \\
\text { rural }\end{array}$ & $\begin{array}{c}\text { Clero } \\
\text { astorgano }\end{array}$ & Conventos & Cofradias & Parroquias & Hidalgos \\
\hline Murias de Rechi. ...... & & 1 & & 3 & & \\
\hline Morales del Arced. .... & & 1 & & & & 1 \\
\hline Valdespino & & & 3 & 1 & 1 & \\
\hline Sta. Catalina ......... & & 1 & 2 & & & \\
\hline Quintanilla $\ldots \ldots \ldots \ldots$ & & & 7 & 1 & & \\
\hline Molinaferrera ... & & 3 & 2 & 1 & 3 & 1 \\
\hline Santiagomillas $\ldots . .$. & & 1 & 3 & 7 & & \\
\hline Lucillo & 1 & & 3 & 5 & & \\
\hline Murias Pedredo .. & & & 3 & 2 & & \\
\hline Pobladura . . & 1 & 1 & 4 & 2 & 1 & \\
\hline TOTAL (66) $\ldots \ldots \ldots$ & 2 & 8 & 27 & 22 & 5 & 2 \\
\hline$\%$ & 3 & 12,1 & 41 & 33,3 & 7,6 & 3 \\
\hline
\end{tabular}

\subsection{Los censatarios}

Junto a los censualistas, los demandantes del capital o censatarios ocupan un lugar destacado en estas operaciones crediticias. No sólo se 
trata de conocer qué grupos sociales solicitan los préstamos censales y los motivos que le mueven a ello, sino también las variaciones que se pueden experimentar al respecto, sobre todo en el siglo XVIII. Como resulta obvio y comprobable en las sucesivas tablas la mayoría de los censatarios tienen procedencia rural, lo que supone una constante a lo largo de la Edad Moderna. No obstante, hay que diferenciar los resultados obtenidos de los protocolos astorganos y de los del área rural maragata, pues mientras éstos últimos reflejan la procedencia de los censatarios maragatos, los primeros, dada la dispersión geográfica, podrían llevarnos a unificar comportamientos de zonas geográficas distintas.

Así, mediante el Catastro de 1752 obtenemos los siguientes resultados sobre el origen geográfico de los censatarios, demandantes de capital astorgano:

\begin{tabular}{|c|c|c|}
\hline PROCEDENCIA & N. ${ }^{\circ}$ CENSOS & $\%$ \\
\hline Bierzo Alto & 63 & 37 \\
\hline Páramo-Ribera & 37 & 21,8 \\
\hline Maragatería y Cabrera . & 39 & 23 \\
\hline Labradores locales ... & 8 & 4,7 \\
\hline Hidalguía & 7 & 4,1 \\
\hline Clero..... & 0 & 0 \\
\hline Profesiones liberales. & 15 & 8,8 \\
\hline Concejos & 1 & 0,6 \\
\hline TOTAL & 170 & 100 \\
\hline
\end{tabular}

Queda claro a través de la presente tabla que Astorga es un centro multicomarcal en cuanto al capital censal y es de destacar el 37 por 100 
de los censos que constituyen personas procedentes del Alto Bierzo, lo que se comprende si tenemos en cuenta las características sociales y la proximidad geográfica. La Maragatería ocupa el segundo lugar con el 23 por 100 de los censos constituidos en Astorga, aunque también del Páramo leonés acuden a la ciudad de Astorga en busca de capital; donde, como vimos, el peso del clero tanto secular como regular era muy fuerte. Solamente el 16 por 100 de los censos son solicitados por diferentes grupos sociales astorganos entre los que sobresalen, por otra parte de forma comprensible dado su número, los profesionales de la pluma u oficios liberales.

Asi pues, las escrituras censales astorganas nos aportan, respecto al origen socio-profesional de los censatarios de todos las zonas anteriormente especificadas, los siguientes resultados:

\begin{tabular}{|c|c|c|c|c|c|c|c|c|}
\hline \multirow{2}{*}{ CENSATARIOS } & \multicolumn{2}{|c|}{$1620-1650$} & \multicolumn{2}{|c|}{$1650-1700$} & \multicolumn{2}{|c|}{$1700-1750$} & \multicolumn{2}{|c|}{$1750-1810$} \\
\hline & n. ${ }^{\circ}$ & $\%$ & $n .^{\circ}$ & $\%$ & $\mathrm{n}^{\circ}$ & $\%$ & n. ${ }^{\circ}$ & $\%$ \\
\hline Labradores & 132 & 80 & 180 & 81,8 & 49 & 57,6 & 16 & 32 \\
\hline Clero & 0 & 0 & 0 & 0 & 1 & 1,2 & 0 & 0 \\
\hline Prof. liberales ... & 0 & 0 & 3 & 1,3 & 11 & 12,9 & 11 & 22 \\
\hline Comerciantes $\ldots \ldots \ldots \ldots \ldots$ & 9 & 5,5 & 11 & 5 & 8 & 9,4 & 10 & 20 \\
\hline Hidalguía (Don) & 0 & 0 & 0 & 0 & 3 & 3,5 & 7 & 14 \\
\hline Concejos & 3 & 1,8 & 9 & 4 & 5 & 5,9 & 0 & 0 \\
\hline Sin identificar $\ldots \ldots \ldots \ldots \ldots$ & 21 & 12,7 & 17 & 7,7 & 8 & 9,4 & 6 & 12 \\
\hline TOTAL & 165 & 100 & 220 & 100 & 85 & 100 & 50 & 100 \\
\hline
\end{tabular}


Un primer aspecto a resaltar en la tabla anterior es la uniformidad en los resultados de los dos períodos establecidos para el siglo XVII, antes de que el tipo de interés censal se redugera al 3 por 100 . Así, durante el siglo XVII en torno al 80 por 100 de los censos solicitados se hacen por parte del campesino (incluso más si añadimos el porcentaje de desconocidos). Este, como se ve, utiliza mayoritariamente el sistema clásico de financiación, a la vez que en lugares secundarios en cuanto a participación tenemos a comerciantes $(5,5 \%)$ y concejos locales.

Durante el siglo XVIII, en el que, como vimos, se reduce el capital censal, se producen importantes variaciones. Seguimos viendo cómo el sector agrario se lleva cerca del 50 por 100 de los censos, pero la pérdida ha sido muy fuerte con respecto al siglo anterior, canalizándose el crédito censal hacia otros sectores económicos, sobre todo hacia las profesiones liberales que alcanzan en la segunda mitad del siglo el 22 por 100 y hacia los sectores comerciales (comerciantes, arrieros) con el 20 por 100 . Esto unido a que el 14 por 100 de los censos de dicho período son demandados por grupos rentistas (hidalgos), nos permite llegar a la conclusión, toda vez que estos porcentajes se incrementan sucesivamente desde la primera mitad del siglo XVIII, de que el capital censal en dicho siglo, y de forma progresiva, se fue haciendo más selectivo y se dirigió hacia un campesinado clásico y acomodado con medios o tierras que hipotecar y hacia otros sectores sociales que, como la burguesís comercial y los arrieros deseaban incrementar sus negocios aprovechando la coyuntura económica favorable que se les ofrecia y el incremento de los efectivos humanos que promovieron el incremento de la demanda.

Por lo que respecta al área rural maragata, las escrituras censales nos ofrecen unos resultados que se ajustan, en su medida, a lo expuesto anteriormente: 
Deudores, rentistas y prácticas crediticias en la sociedad leonesa

\begin{tabular}{|c|c|c|c|c|c|c|c|c|}
\hline \multirow{2}{*}{ CENSUATARIOS } & \multicolumn{2}{|c|}{$1620-1650$} & \multicolumn{2}{|c|}{$1650-1700$} & \multicolumn{2}{|c|}{$1700-1750$} & \multicolumn{2}{|c|}{$1750-1810$} \\
\hline & $n .^{\circ}$ & $\%$ & $\mathrm{n} .^{\circ}$ & $\%$ & $n .^{\circ}$ & $\%$ & n. ${ }^{\circ}$ & $\%$ \\
\hline Labradores ........... & 29 & 56,8 & 58 & 65,9 & 10 & 45,5 & 7 & 43,7 \\
\hline Clero & 0 & 0 & 0 & 0 & 0 & 0 & 0 & 0 \\
\hline Prof. liberales & 2 & 3,9 & 8 & 9 & 0 & 13,6 & 4 & 25 \\
\hline Comerciantes $\ldots \ldots \ldots$. & 0 & 0 & 3 & 3,4 & 2 & 9 & 3 & 18,7 \\
\hline Hidalguía (Don) .. & 0 & 0 & 0 & 0 & 0 & 0 & 0 & 0 \\
\hline Concejos....... & 9 & 17,6 & 6 & 6,8 & 1 & 4,5 & 0 & 0 \\
\hline Sin identificar & 10 & 19,6 & 13 & 14,8 & 6 & 27,3 & 2 & 12,5 \\
\hline TOTAL & 51 & 100 & 88 & 100 & 22 & 100 & 16 & 100 \\
\hline
\end{tabular}

En efecto, durante el siglo XVII la mayoría de los censos se canalizan hacia el mundo rural. Si al porcentaje campesino se añaden los no identificados, presumiblemente también campesinos, nos acercaríamos al 80 por 100 del total de censos constituidos. A éstos hay que unir la parte correspondiente a los concejos que en el siglo XVII hipotecan sus bienes o los de los vecinos, de forma colectiva, para obtener créditos, si bien, el porcentaje de participación se ve reducido considerablemente, dado que se pasa del 17 por 100 en la primera mitad del siglo XVII al 0 de la segunda del XVIII.

Pero como ocurriese con los censos recogidos en la notaría astorgana, a lo largo del siglo XVIII se aprecia un desvío de capital censal hacia otros grupos sociales o sectores económicos. Nuevamente las profesiones liberales, entre las que destacan los notarios o escribanos, acuden al censo en porcentajes importantes que alcanzan en la segunda mitad del siglo XVIII de los escasos censos que se constituyen. Aunque de forma mayoritaria va a ser el campesinado medio o rico, a juzgar por los bienes inmuebles hipotecados, los que tomen dinero en censo, también durante el siglo XVIII una parte importante de este capital censal, 
reducido con respecto al siglo anterior, es demandado por grupos sociales no rurales, pero directamente ligados y dependientes del mundo rural, entre los que encontramos a determinados comerciantes de paños y mantas, así como a hombres dedicados a la arriería. Esta variación viene a confirmar, una vez más, nuestra teoría de que el censo, como forma crediticia moderna, no sólo pierde fuerza durante el siglo XVIII, sino que cumple, dentro del campo económico, una función algo distinta con respecto al siglo XVII.

\section{Las obligaciones}

Junto a los censos, las denominadas obligaciones o "ventas al fiado" se convierten en el instrumento de crédito que se va imponiendo de forma clara durante el siglo xvIII. Este tipo de imposiciones fluctúa, en cierto modo, de forma contraria al censo, ya que, mientras el número de censos constituidos desciende durante coyunturas recesivas, el de obligaciones se incrementa considerablemente. Por eso, cada vez más llegamos al convencimiento de que estos dos instrumentos posibles de endeudamiento guardan entre sí importantes diferencias, algunas de ellas ya apuntadas. Así, el hecho de solicitar capital por medio de un censo conlleva establecer una hipoteca que no todos disponen de ella y que en coyunturas recesivas o crisis coyunturales se corre el riesgo de perder ante las dificultades en el pago de los réditos o intereses. Esto hace que los censos en estas situaciones aporten un mayor riesgo para el demandante del préstamo. Por el contrario, en las obligaciones el endeudamiento se hace menos tajante o directo al no existir hipoteca y ante la posibilidad de demora, que de hecho tenemos constancia de que se daba, sobre todo entre la burguesia comercial que, en cierto modo, dependia también de la economía agraria.

El campesino acude a ésta y a otros grupos rentistas, sobre todo en crisis coyunturales, a solicitar o bien dinero o bien grano para alimentarse o poder sembrar la sementera. Los comerciantes, ante la falta de eraria entre los grupos campesinos, tienen que flexibilizar las formas de venta si quieren obtener ganancia en sus negocios. Por eso, las obligaciones que, a priori, son más flexibles y menos peligrosas, aunque más usureras, se pueden convertir, y de hecho se convierten en un alto porcentaje, en medio de endeudamiento casi constante, de un sector importante del campesinado y del mundo artesanal. 


\subsection{Tipología de las Obligaciones}

A fin de conocer la tipología de las escrituras de obligación más frecuentes hemos recogido una muestra, tanto en Astorga como en el área rural maragata, con la que establecimos cinco períodos y obtuvimos los siguientes resultados:

\begin{tabular}{|c|c|c|c|c|}
\hline \multirow{2}{*}{ TIPOLOGÍA } & \multicolumn{2}{|c|}{ ASTORGA } & \multicolumn{2}{|c|}{ ÁREA RURAL } \\
\hline & $\mathrm{n}^{\circ}$ & $\%$ & $n^{\circ}$ & $\%$ \\
\hline \multicolumn{5}{|l|}{$1620-1650$} \\
\hline Préstamo monetario & 51 & 21,5 & 73 & 45,3 \\
\hline Ventas al fiado $\ldots \ldots \ldots \ldots \ldots \ldots$ & 61 & 26 & 31 & 19,3 \\
\hline Préstamo o venta de granos ....... & 101 & 42,4 & 38 & 23,6 \\
\hline Reconocimiento de deudas y rentas & 9 & 3,8 & 9 & 5,6 \\
\hline Cargas por pleitos $\ldots \ldots \ldots \ldots \ldots$ & 3 & 1,2 & 2 & 1,3 \\
\hline Obligados y rentas $\ldots \ldots \ldots \ldots \ldots$ & 12 & 5,1 & 8 & 4,9 \\
\hline TOTAL & 237 & 100 & 161 & 100 \\
\hline
\end{tabular}




\begin{tabular}{|c|c|c|c|c|}
\hline \multirow{2}{*}{ TIPOLOGIA } & \multicolumn{2}{|c|}{ ASTORGA } & \multicolumn{2}{|c|}{ ÁREA RURAL } \\
\hline & $n^{\circ}$ & $\%$ & $n^{\circ}$ & $\%$ \\
\hline \multicolumn{5}{|l|}{$1651-1680$} \\
\hline Préstamo monetario & 114 & 39,5 & 68 & 36,3 \\
\hline Ventas al fiado & 93 & 32,1 & 42 & 22,5 \\
\hline Préstamo o venta de granos $\ldots . . .$. & 66 & 22,8 & 58 & 31 \\
\hline Reconocimiento de deudas y rentas & 3 & 1 & 0 & 0 \\
\hline Cargas por pleitos $\ldots \ldots \ldots \ldots \ldots$. & 4 & 1,3 & 9 & 4,8 \\
\hline Obligados y rentas & 9 & 3,1 & 10 & 5,3 \\
\hline TOTAL . & 289 & 100 & 187 & 100 \\
\hline \multicolumn{5}{|l|}{$1680-1710$} \\
\hline Préstamo monetario & 36 & 22 & 21 & 15,8 \\
\hline Ventas al fiado .. & 35 & 21,3 & 36 & 26,3 \\
\hline Préstamo o venta de granos ... & 72 & 43,9 & 63 & 46 \\
\hline Reconocimiento de deudas y rentas & 10 & 6 & 13 & 9,4 \\
\hline Cargas por pleitos $\ldots \ldots \ldots \ldots \ldots \ldots$. & 0 & 0 & 2 & 1,5 \\
\hline Obligados y rentas $\ldots \ldots \ldots \ldots \ldots$ & 11 & 6,7 & 2 & 1,5 \\
\hline TOTAL .. & 164 & 100 & 137 & 100 \\
\hline
\end{tabular}


Deudores, rentistas y prácticas crediticias en la sociedad leonesa

\begin{tabular}{|c|c|c|c|c|}
\hline \multirow{2}{*}{ TIPOLOGÍA } & \multicolumn{2}{|c|}{ ASTORGA } & \multicolumn{2}{|c|}{ ÁREA RURAL } \\
\hline & n. & $\%$ & $n^{\circ}$ & $\%$ \\
\hline \multicolumn{5}{|l|}{$1711-1750$} \\
\hline Préstamo monetario $\ldots \ldots \ldots \ldots \ldots$ & 15 & 7,4 & 11 & 6,9 \\
\hline Ventas al fiado...... & 64 & 31,7 & 36 & 22,7 \\
\hline Préstamo o venta de granos $\ldots \ldots \ldots$ & 71 & 35,1 & 69 & 43,7 \\
\hline Reconocimiento de deudas y rentas & 33 & 16,3 & 28 & 17,7 \\
\hline Cargas por pleitos $\ldots \ldots \ldots \ldots \ldots \ldots$ & 5 & 2,5 & 8 & 5 \\
\hline Obligados y rentas $\ldots \ldots \ldots \ldots \ldots$ & 14 & 6,9 & 6 & 3,8 \\
\hline TOTAL $\ldots \ldots \ldots$ & 202 & 100 & 158 & 100 \\
\hline \multicolumn{5}{|l|}{$1751-1800$} \\
\hline Préstamo monetario $\ldots \ldots \ldots \ldots \ldots$ & 29 & 11,5 & 17 & 8,4 \\
\hline Ventas al fiado $\ldots \ldots \ldots \ldots \ldots \ldots$ & 61 & 24,1 & 24 & 11,9 \\
\hline Préstamo o venta de granos $\ldots . . .$. & 142 & 56,1 & 125 & 61,9 \\
\hline Reconocimiento de deudas y rentas & 9 & 3,6 & 19 & 9,4 \\
\hline Cargas por pleitos & 3 & 1,2 & 11 & 5,4 \\
\hline Obligados y rentas & 9 & 3,6 & 6 & 3 \\
\hline TOTAL & 253 & 100 & 202 & 100 \\
\hline
\end{tabular}


Aunque existe uniformidad en todo el período de estudio sobre la imposición mayoritaria de tres tipos de obligaciones, es de destacar, como es obvio, el predominio de las denominadas ventas de crédito o “al fiado" que en los cinco períodos superan más del 50 por 100 del conjunto de obligaciones. Dentro de éstas hemos diferenciado las ventas a crédito de productos de consumo de las obligaciones emanadas de los préstamos o ventas al fiado de granos, ya para consumo, ya para siembra. Lo que parece estar perfectamente claro es el fuerte peso que este tipo de formas crediticias tiene en el proceso económico y comercial moderno. La precariedad de los recursos de gran parte del campesinado, principal implicado en este tipo de operaciones, hace que, sobre todo en coyunturas recesivas, acuda masivamente a estas ventas a crédito, a las que se ve inducido, incluso para poder subsistir.

El segundo lugar lo ocupan los préstamos monetarios cuya imposición se ve reducida de forma ostensible en determinadas fases recesivas o coyunturales económicas críticas, aunque resulta significativo el descenso de la segunda mitad del siglo XVIII al 8,4 por 100 en el área rural $y$ al 11,5 por 100 en Astorga. El campesino parece rehusar el préstamo monetario y se acerca más durante el siglo XVIII a la venta a crédito de los productos que demanda.

El hecho de que en el siglo XVIII se imponga de forma casi absoluta la obligación como medio crediticio de financiación viene a significar que este tipo de economía agraria se mueve con formas arcaicas y sobre bases tradicionales. El escaso poder adquisitivo de más del 50 por 100 de los campesinos provoca un sistema económico y comercial casi medievalista.

\subsection{El préstamo monetario}

Al silenciar, por lo general, las escrituras los motivos de la petición de estos préstamos no podemos conocer un aspecto importante de este tipo de forma crediticia. No obstante, queda claro que éstas alcanzan un porcentaje destacado en el conjunto de las obligaciones, porcentaje que en las dos muestras desciende considerablemente durante el siglo XVIII, pues se pasa en el área rural del 45,3 por 100 de la primera mitad de siglo al 8,4 por 100 de la segunda. La economía de subsistencia y la escasez de recursos generados por la ausencia de excedentes que comercializar, obligan a los grupos más débiles, artesanos y pequeños campesinos, a solicitar préstamos en dinero para acometer, desde un 
gasto imprevisto, hasta la compra de bienes y productos indispensables para subsistir.

Resulta harto dificil conocer el nivel de especulación y usura de este tipo de operaciones ya que el perceptor o deudor solamente deja constancia de su gratitud por la "buena obra", pero es sabido que éste es un mero formalismo, que se repite en todas las escrituras de este tipo y que dichos préstamos pueden ya englobar, en la cantidad a devolver, el porcentaje de los intereses. En estas operaciones juega un importante papel la oferta y la demanda y en gran medida se oculta y legaliza una práctica que era rechazada incluso por la misma Iglesia católica.

\subsection{Las ventas a crédito de productos de consumo}

Es bien sabido, incluso en el mundo rural contemporáneo, que el campesino carecia durante determinadas épocas del año de dinero con el que saldar sus deudas. Solamente durante la estación otoñal estaba en buenas condiciones, vendido el producto escedentario de la cosecha, de afrontar los pagos y las deudas contraídas durante el año cosecha anterior. Pero el problema surge cuando esta posibilidad o medio de obtener erario se frustraba ante una crisis económica y en coyunturas en las que era, incluso, difícil la autosubsistencia.

A lo largo del año el campesino hacía sus compras, generalmente en productos elaborados por el sector secundario para su uso personal (paños, etc.) o para el desarrollo de las faenas agrarias, incluidos animales y simientes. Raramente se realiza el pago en efectivo y es mayoritariamente mediante estas escrituras de obligación como se desarrolla el proceso comercial.

Nada se especifica en las escrituras sobre recargos o incremento del precio con respecto a las compras al contado, no obstante, y teniendo en cuenta que el plazo de cobro se sitúa entre dos y seis meses, coincidiendo siempre con meses otoñales, creemos que no se produce variación alguna en el precio de los productos adquiridos al fiado, pues, por las razones antes apuntadas, el dinamismo del mercado estuvo siempre apoyado sobre este sistema de venta a crédito.

En la propia escritura de obligación se hace constar la deuda en dinero, así como el concepto, lo que facilita importante información sobre 
otros aspectos de la actividad comercial como tipos de productos y su procedencia:

"...es a saver ciento y cinquenta y seis reales de buena moneda usual y corriente al tiempo de la paga, los quales confieso deberle y son por razon de otros tantos en que el sia de oy me ha vendido nueve baras de paño deceno de Yzcar, pardo, a precio de diez y seis reales la bara y quatro baras de bayeta de la tierra a precio de tres reales la bara, que todo junto haze la dicha cantidad, del qual dicho paño y bayeta me doy por contento y satisfecho... para dar y pagar los dichos ciento y cinquenta y seis reales todos juntos y en una paga para el dia de Nuestra Señora de Agosto..." ${ }^{17}$.

\subsection{El préstamo y la venta de granos}

Como ya comprobamos, y por otra parte es obvio, en un marco rural como en el que nos movemos, las obligaciones impuestas sobre la comercialización de granos ocupan el primer lugar en importancia cuantitativa. Queda claro que a través de las distintas formas de venta a crédito los grupos rentistas, es decir aquellos que reciben el excedente agrario mediante la detracción de rentas e impuestos (clero e hidalguía), especulan con sus granos mediante formas más o menos marcadas por la usura, que buscan en la mayoría de los casos, la obtención de un mayor precio y rendimiento de sus rentas.

Es bien conocido que el 50 por 100 de los campesinos son deficitarios y su poder adquisitivo es fuertemente dependiente del desarrollo y signo de las coyunturas economicas. Este hecho, cuyo origen o causas primarias se sitúan en factores estructurales, paradójicamente se ve amortizado por este sistema de comercialización que, a primera vista, se puede evaluar como un remedio beneficioso para el campesino deficitario, pero que a medio y largo plazo le puede acarrear graves perjuicios.

La forma más común en este tipo de ventas de grano a crédito es la entrega del producto por parte del acreedor, previo reconocimiento y obligación del deudor de hacerlo efectivo en un plazo determinado, por lo general en agosto o septiembre, y a los precios que alcancen durante

17 AHPL Caja 9489 (460). 
los meses de soldadura, con lo que el rentista garantiza la venta de su producto al mayor precio alcanzado durante el año cosecha:

"es a saber el balor de nueve cargas de centeno y quatro cargas de trigo que por hazernos merced y buena obra oy dia de la fecha a vendido al fiado, para socorro y alimento de nuestras personas y familias... cuyas nueve cargas de centeno y quatro de trigo le hemos de pagar a las mayores balias que tuviesen dichos granos en los mercados que se celebraron en esta ziudad por los meses de mayo y junio deste presente año..." ${ }^{18}$.

Por otra parte, son muy raros los casos en los que se especifica de antemano el precio al que se ha de pagar el grano vendido al fiado. Aunque en menor medida se encuentran obligaciones en las que se acuerda la simple devolución de los granos prestados al siguiente año cosecha, lo que es normal en años en los que los precios del cereal son bajos 0 se han reducido considerablemente con respecto a otros ciclos expansivos. Con ello el acreedor o rentista busca la especulación y la posibilidad de estar en posesión de grano en años de mejor venta y precios más elevados, dado que no necesita de esos recursos para sobrevivir.

Una tercera forma, aunque mucho más reducida, es el simple préstamo con la única condición de ser devuelto en la misma especie y calidad en un plazo fijado. Lo que a primera vista puede parecer una "merced y buena obra" no cabe duda que encierra algunos beneficios para los prestamistas, ya que esta práctica, como la anterior, se detecta en años de precios bajos y posiblemente con campesinos pobres o muy deficitarios. Con ella se busca la garantía de poder poseer grano que comercializar en años de mejores precios, aparte de otras contrapartidas que pueden omitirse en las escrituras. El riesgo corrido por el campesino es grande, sobre todo cuando se trata de campesinos deficientes con pequeñas explotaciones, ya que desconoce si en la próxima cosecha podrá obtener excedente que le permita devolver el préstamo, con lo que el endeudamiento puede consolidarse hasta producirle la ruina total.

\footnotetext{
18 AHPL Caja 10189 (2031). Fol. 139.
} 
Este tipo de operaciones suele hacerse en épocas de siembra (otoñoinvierno) y también durante los últimos meses del año cosecha ${ }^{19}$.

\subsection{Prestamistas y prestatarios}

Una vez conocida la tipología y dinámica de las principales obligaciones en la Maragatería, se hace necesaria la aclaración de otros aspectos, en el ámbito cronológico-evolutivo, sobre los grupos protagonistas en la constitución de dichas formas crediticias.

Respecto a los deudores $\mathrm{u}$ obligados hay que diferencialos conforme al tipo de obligaciones, pues las referentes a cargas por pleitos y, sobre todo, los obligados de rentas decimales y otros arriendos están directamente ligadas a campesinos ricos y a otros grupos acomodados del sector terciario (comerciantes, profesionales liberales, etc.).

Pero, tanto ventas al fiado como préstamos de dinero y granos se hallan estrechamente ligados al mundo rural, aunque también se aprecia la participación del sector artesanal de las villas. Los condicionantes estructurales agrarios; la existencia de un fuerte contingente de pequeños y deficientes campesinos; la propia dinámica comercializadora de una agricultura tradicionalista y en gran medida estancada; la inestabilidad de la producción agraria con sucesión de coyunturas fuertemente recesivas, son algunos de los factores más importantes que explican la dinámica e imposición de estas formas crediticias u obligaciones.

Asi pues, mientras que en la Maragatería, como en otras comarcas leonesas, los deudores proceden, en su gran mayoria, del campo, el

19 AHPL Caj. 10178 (2020):

"Sepase como nos Manuel Gonzalez y Manuel de Cavo, vecinos del Val de San Lorenzo... nos obligamos con nuestras personas y bienes muebles y rayzes presentes y futuros de dar y pagar y que daremos y pagaremos realmente y con efecto a D. J. Nieto, canonogo de la Sta. I. catedral de esta ciudad de Astorga y en su nombre a quien su or-den tenga, quatro cargas de centeno de buen pan, seco, limpio, sin mezcla de semilla alguna, de dar e tomar, medidas con la de Avila, al tiempo de la paga y dichas quatro cargas de centeno son las mismas que hoy dia de la fecha nos a dado prestadas de las quales nos damos por entregados y satisfechos a nuestra voluntad... y las hemos de pagar juntas para el dia de Ntra. Sra. de Septiembre de este presente año...". 
origen social de los acreedores o prestamistas se hace necesario buscarlo entre las clases sociales rentistas, ya que son ellos los que, a través del control y propiedad de los medios de producción (tierra, ganado), asi como de rentas, canalizan hacia sí la mayor parte del excedente agrario.

\begin{tabular}{|c|c|c|c|c|c|c|c|c|c|c|}
\hline \multirow{2}{*}{$\begin{array}{l}\text { ACREEDORES } \\
\text { Canónigo y jerar- } \\
\text { quias eclesiásti- } \\
\text { cas astorganas }\end{array}$} & \multicolumn{2}{|c|}{$\begin{array}{r}1620-1650 \\
n^{\circ}\end{array}$} & \multicolumn{2}{|c|}{$1651-1680$} & \multicolumn{2}{|c|}{$1681-1720$} & \multicolumn{2}{|c|}{$1721-1750$} & \multicolumn{2}{|c|}{$\begin{array}{r}1751-1800 \\
0\end{array}$} \\
\hline & 41 & 27 & 34 & 18,9 & 31 & 28,5 & 23 & 26,1 & 47 & 27,5 \\
\hline Clero rural & 36 & 23,7 & 49 & 27,2 & 17 & 15,5 & 16 & 18,2 & 38 & 22,2 \\
\hline Nobleza & 31 & 20,2 & 51 & 28,3 & 26 & 23,8 & 11 & 12,5 & 36 & 21 \\
\hline Burguesia com. & 17 & 11,2 & 21 & 11,6 & 12 & 11 & 29 & 33 & 17 & 10 \\
\hline Prof. liberales & 21 & 13,8 & 16 & 8,9 & 21 & 19,3 & 10,2 & 33 & 19,3 & \\
\hline Cofradias & 6 & 3,9 & 9 & 5 & 2 & 1,8 & 0 & 0 & 0 & 0 \\
\hline Conventos & 0 & 0 & 0 & 0 & 0 & 0 & 0 & 0 & 0 & 0 \\
\hline TOTAL $\ldots \ldots \ldots$ & 152 & 100 & 180 & 100 & 109 & 100 & 88 & 100 & 171 & 100 \\
\hline
\end{tabular}

A la hora de establecer los períodos cronológicos en la tabla anterior intentamos acoplarlos a los ciclos más significativos del desarrollo económico, con la intención de buscar variaciones importantes en el tiempo. Pero, al contrario que en otras tablas referentes a las formas de financiación, aqui el comportamiento es muy similar durante todo el período, dado que el clero secular astorgano acapara entre el 26 y el 28 por 100 de las obligaciones que son generalmente ventas al fiado de granos. También el clero rural tiene una destacada participación que sobrepasa el 20 por 100 , lo que en conjunto sitúa al clero secular en torno al 50 por 100 de las obligaciones. A su vez, otros grupos sociales como la 
nobleza que, como vimos, en el siglo XVIII se alejan del censo como forma de inversión, sitúan su participación al mismo nivel que el propio clero secular astorgano. También, aunque en un nivel menor cercano al 11 por 100 , se halla la burguesía comercial y las profesiones liberales. La primera entre 1720-1750, fase clave en el desarrollo agrario, constituye nada menos que el 33 por 100 de las obligaciones. Este ascenso, aunque en la segunda mitad de siglo, se aprecia también en las profesiones liberales $\mathrm{y}$, como era de esperar, otras instituciones eclesiásticas como las cofradias y el clero regular apenas dejan constancia de su participacion en estas formas crediticias para las que se exige el constante control y seguimiento del capital invertido. Como vimos anteriormente ambas instituciones religiosas habían optado por la seguridad y garantía de los censos consignativos al quitar.

\section{CONCLUSIONES}

Después de este repaso sobre los aspectos más fundamentales de las diferentes formas crediticias modernas en la ciudad de Astorga se hace necesaria una valoración en conjunto, aunque en algunos aspectos ha de quedarse en mera hipótesis o reflexión ya que las fuentes ocultan aspectos importantes de carácter individual.

En primer lugar y en cuanto al censo una de las primeras reflexiones a realizar, sobre todo después de los ataques de arbitristas como Mercado, Moncada, etc., es si este instrumento de crédito cumplió una función negativa en el desarrollo económico agrario y fue el causante de los males y de la precariedad de la agricultura y del conjunto de la economía maragata. Después de lo visto a lo largo del trabajo, podemos afirmar que no, que el censo fue en ese contexto de anquilosamiento estructural una forma crediticia que reunía condiciones muy beneficiosas para el censatario (bajo interés, plazo de devolución, etc.). Dudamos que las instituciones eclesiásticas, principales censualistas, obtuvieran mucha tierra mediante la insolvencia de los censatarios con la consiguiente pérdida de los bienes hipotecados, porque el censo se convierte poco a poco en un instrumento crediticio de privilegiados y ante la mayor demanda, sobre todo en el siglo XVIII, los censualistas escogen bien a censatarios solventes y con medios de producción. 
Pero el capital censal tampoco se canalizó hacia reformas importantes en el área de los avances técnicos y dentro de la cultura agraria, sino más bien sirvió de remedio temporal a determinados grupos que, más que invertir en nuevas formas, intentaban un mayor enriquecimiento en el contexto de una economia agraria tradicional.

Ese carácter beneficioso y rentable del censo, sobre todo en el siglo XVIII, se descubre cuando vemos que parte del capital censal se desvía hacia campesinos solventes que siguen comprando tierra y ganando a sus convencinos endeudados o hacia grupos burgueses y rentistas que, no sólo adquieren cada vez más tierra, sino que ante el resurgir económico de las primeras décadas del siglo xvIII y al igual que ocurriese en la vecina villa de La Bañeza, utilizan el ganado vacuno como medio rentable de inversión que le permite una mayor participación en el producto agrario.

Por esto no creemos que el censo como tal fuese perjudicial al proceso económico agrario, sino más bien todo lo contrario, ya que un porcentaje importante de los campesinos tuvo en él un remedio temporal, sobre todo en el siglo XVII cuando se puso de nuevo en marcha el proceso agrario.

Sin embargo, otra cosa muy diferente son las denominadas Obligaciones. Sin duda estas formas, sobre todo las ventas al fiado, venían impuestas por el mismo sistema comercial y sobre todo por la carencia de erario, durante gran parte del año, de un porcentaje importante del conjunto social.

La propia dinámica de las obligaciones a las que accedian todos los grupos sociales les infunde un grado de tolerancia y libertad, lo que puede llegar a ser enormemente perjudicial para los sectores agrarios y urbanos más deprimidos. El mismo aplazamiento de las deudas de un año para otro; el sucesivo endeudamiento mediante estas formas crediticias con grupos sociales privilegiados conducen al campesino o artesano deudores hacia la pérdida de sus propios bienes de producción. Este sistema permitió a la burguesía comercial de las villas y ciudades leonesas conectar e introducirse de lleno en el mundo agrario y sobre todo en el siglo XVIII de forma altamente rentable.

A su vez, permitió a estos y otros sectores sociales, como el clero secular, obtener importantes beneficios del producto de sus rentas, me- 
diante la especulación y venta anticipada de los granos a los precios más altos.

Estos y otros aspectos característicos de estas formas crediticias convierten a las obligaciones, en mucha mayor medida que los censos, en instrumento de sujeción del campesino, así como en portadores de graves males para los sectores sociales más marginales, pero también necesarias, mientras no se produjera variación alguna en las estructuras socio-económicas, para el desarrollo económico agrario de la modernidad. Lógicamente el origen del problema se halla en la situación de las propias estructuras, tanto en la desigual distribución de los medios de producción, como en la falta de reformas cualitativas en la agricultura, pasando por la ausencia total de inversiones por parte de los propietarios de los medios y de la carencia de un sistema eficaz de comercialización y de canalización de los excedentes agrarios.

Pero lo que N. Salomon hacía extensivo a los censos de Castilla la Nueva como responsables de la ruina del campo y de que el campesino cayese en el siglo XVI en "una especie de semiservidumbre", nosotros lo centraríamos, más que en el censo, en las obligaciones, sin que ello suponga una negación de las consecuencias negativas que la imposibilidad de pagar los réditos censales podía acarrearle al censatario. No obstante, es de destacar que no hallamos ningún caso al respecto entre las miles de escrituras examinadas ${ }^{20}$.

${ }^{20}$ N. SALOMÓN: La vida rural..., p. 255 :

«En la práctica estos censos funcionan en manos de sus detentadores como un instrumento de sujeción del campesinado. En caso de falta de pago de la renta prevista por el contrato, el prestamista podía apoderarse de los bienes del campesino, hacerle quebrar. El pacto económico que éste habia acordado con el amo de nuevo tipo, el poseedor del dinero, le ligaba tan estrechamente como los antiguos pactos señoriales pudieron atar los siervos a su señor. En cierto sentido, el campesino endeudado también se convertía en vasallo del nuevo amo. Así surgió en el campo castellano, hacia fines del siglo XVI, una especie de semiservidumbre por deudas...". 